\title{
ATIVA: Um Ambiente Virtual para Apoiar o Ensino e Aprendizagem de Aluno com Deficiência Intelectual
}

\author{
Vinicius Schultz Garcia da Luz, UTFPR, viniciusluz@alunos.utfpr.edu.br, https://orcid.org/0000-0002-9616-3503 \\ Paulo Victor Rios Pinto, UTFPR, paulop.2019@alunos.utfpr.edu.br, https://orcid.org/0000-0001-6584-1474 \\ Simone Nasser Matos, UTFPR, snasser@utfpr.edu.br, https://orcid.org/0000-0002-5362-2343 \\ Helyane Bronoski Borges, UTFPR, helyane@utfpr.edu.br, https://orcid.org/0000-0002-9153-3819
}

Resumo: Este artigo apresenta um ambiente virtual, denominado de Ativa, que tem a finalidade de permitir aos professores de instituições de ensino de alunos com deficiência intelectual (DI) gerenciar as atividades de suas aulas por meio de jogos sérios, o coordenador pedagógico gerenciar as turmas e o aluno executar a aula. A pesquisa é de natureza aplicada e usou da observação nas aulas de informática em uma instituição de modalidade de educação especial da região para relatar e identificar os requisitos do ambiente. $\mathrm{O}$ ambiente foi criado usando a metodologia Rapid Application Development (RAD) e envolveu a criação de quatro módulos. Como resultado o Ativa permite ao professor reusar aulas que já estão cadastradas, mantém uma base de dados sobre os jogos sérios gratuitos que podem ser aplicados aos alunos com DI como fixação de conteúdo, é um ambiente integrado contendo aulas de várias matérias e atende as individualidades dos alunos.

Palavras-chave: Deficiência Intelectual. RAD. Ambiente Virtual. Jogos Sérios.

\section{ATIVA: A Virtual Environment to Support the Teaching and Learning of Students with Intellectual Disabilities}

\begin{abstract}
This paper presents a virtual environment, called Ativa, which has the purpose of allowing teachers of educational institutions for the intellectually disabled (ID) to manage the activities of their classes through serious games, the pedagogical coordinator to manage the classes and the student to run the class. The research is of an applied nature and used observation in computer classes at an institution of special education modality in the region to report and identify the requirements of the environment. The environment was created using Rapid Application Development (RAD) methodology and involved the creation of four modules. As a result, Ativa allows the teacher to reuse classes that are already registered, maintains a database on free serious games that can be applied to students with ID as content fixation, it is an integrated environment containing classes of various subjects and meets the individualities of the students.
\end{abstract}

Keywords: Intellectual Disability. RAD. Virtual Environment. Serious Games.

\section{Introdução}

A aprendizagem de pessoas com deficiência intelectual (DI) apresenta um grande desafio para professores de educação inclusiva, pois o ritmo de assimilação de conteúdo e os procedimentos de ensino são mais lentos em virtude de sua condição motora e cognitiva (VINENTE; GALVANI, 2019). A deficiência intelectual (DI) não possui características iguais, mas semelhanças em razão da gravidade. A função da gravidade é distribuída em grau leve, moderado, grave e profundo. Cada indivíduo deve ser avaliado considerando diversos critérios e condições, em que sua avaliação é qualificada conforme o nível de apoio necessário para executar tarefas comuns da vida diária e laboral (Association et al, 2014). Contudo, elas são capazes de aprender a ler, escrever, interagir socialmente e desenvolver habilidades, mesmo que diante de uma compreensão

V. $19 \mathrm{~N}^{\mathrm{o}} 1$, julho, 2021

DOI: https://doi.org/10.22456/1679-1916.118385 RENOTE 
de instrução verbal mais lenta (FONSECA, 2016).

Existem diversas formas e atividades para motivar a aprendizagem de pessoas com deficiência intelectual, sendo que uma delas é a utilização de jogos sérios (GUNTER; KENNY; VICK, 2008), que promove a aproximação de conteúdo pedagógicos com a realidade vivenciada. A aplicação deste recurso é uma tendência tecnológica porque atende necessidades e funções específicas deste público. Para estimular o aluno de educação especial a compreender informações relacionadas ao jogo é necessário utilizar elementos atrativos de acordo com a sua realidade e habilidades. Alguns conceitos de design e funcionalidades podem ser elencadas com professores que trabalham com alunos com deficiência intelectual (FARRINGTON, 2011).

Os trabalhos mostram que as aulas com o auxílio do computador para crianças com DI ajudam em seu desempenho e motivação, pois proporcionam a fixação de conteúdos de matemática (SCHMENGLER, 2019; VENEZIANO et al., 2016), simulam o ambiente de trabalho (PIOVESAN et al., 2015), estabelecem meios para se comunicar melhor (RICALDI et al., 2020), entre outros. Os ambientes virtuais de aprendizagem (AVA) também são considerados recursos que contribuem para o ensino e aprendizagem de alunos com deficiência intelectual porque permitem desenvolver as atividades de forma agradável (MALAQUIAS et al, 2012; CRUZ, 2013; ROSSI, AMORIM; SANTOS, 2020). Os estudos mencionados anteriormente abrangem resultados obtidos a partir de uma disciplina e não existe um ambiente para integrar várias atividades por matérias que possibilite um aluno com DI melhorar sua aprendizagem utilizando jogos sérios.

Este trabalho apresenta um ambiente virtual para o gerenciamento de atividades a serem executadas em uma aula de informática na qual são realizados fixação de conteúdos por meio de uso de jogos sérios. Isto permite ao aluno recordar o que foi visto em sala de aula e aumentar seu aprendizado por meio da tecnologia de informação. A construção do Ativa surgiu após observações realizadas em sala de aula na matéria de informática em uma instituição de modalidade de educação especial da região. $\mathrm{O}$ ambiente proposto foi desenvolvido usando a metodologia RAD (Rapid Application Development) (MARTIN, 1992; ROSYAD et al, 2019) e tecnologias tais como Spring Boot (VMWARE, 2020), Thymeleaf (THYMELEAF, 2020), JPA (APACHE, 2020), entre outras.

\section{Importância do Uso de Jogos Sérios e Ambientes Virtuais na Educação Especial}

A utilização de jogos educacionais promove uma aprendizagem aprimorada e facilitada, pois as informações são absorvidas facilmente por meio de experiências obtidas durante as interações e podem ser transferidas para outras atividades do mundo real. Os jogos educacionais adotam diversas estratégias para promover habilidades cognitivas na qual os alunos aprendem sobre o próprio ambiente escolar executando atividades e se envolvendo com conteúdos e contextos adequados (MELLO; ZENDRON, 2015). Os jogos podem ser enquadrados como uma ferramenta didática de apoio educacional, em que diversos conteúdos podem ser absorvidos de forma interativa e eficiente. A medida que vai avançado no jogo e conhece as regras, potencializa seu conhecimento sobre um determinado assunto (FERREIRA et al., 2018).

Jogos sérios são ferramentas interativas que promovem o desenvolvimento de habilidades e o aprendizado, em que o seu maior objetivo é consolidar o conhecimento ao invés de incentivar apenas o entretenimento. Os elementos de jogos são relacionados a dinâmica de operação e mecânica de como o jogador interage e realiza progressão em um jogo. Os seus componentes são ambientes, cenários, personagens ou representação do jogador (GUNTER; KENNY; VICK, 2008). 
Os jogos sérios tem uma dinâmica para transmitir conceitos e situações alinhadas com questões laborais, educação, saúde, segurança, esportivas, dentre outras, as quais permitem simular experiências lúdicas aproximadas da realidade. Entretanto, são direcionados a um determinado público em que são aplicados conhecimentos específicos relacionados a área de abrangência (MELLO; ZENDRON, 2015). Nesse contexto, por meio da pesquisa de Bigdeli e Kaufman (2017) foi provado que quanto mais próximo for um jogo do ambiente educacional ou da própria realidade do aluno, a aprendizagem será mais produtiva. Estes jogos são projetados para aprimorar habilidades individuais e melhorar algum aspecto de aprendizagem (HAGGLUND, 2012).

A classificação de jogos sérios é baseada nos critérios de jogabilidade, propósito, mercado de atuação e público alvo. Porém, muitos jogos podem ser categorizados sobre o critério de jogabilidade em virtude de sua complexidade, regras, desafios e objetivos (ALVAREZ; DJAOUTI; RAMPNOUX, 2020). Desta forma, a aplicação de jogos sérios pode ser uma forma de aprimoramento de habilidade cognitivas para proporcionar a aproximação do aluno com atividades e experiências do mundo real.

Um exemplo de jogos sérios desenvolvidos para pessoas com DI foi apresentado no trabalho de Bartolomé, Zorrilla e Zapirain (2010) que criou um jogo para aprimorar as habilidades sociais pessoas com deficiência intelectual, direcionado ao público com déficit de atenção, utilizando um controle remoto com a funcionalidade de apontar e clicar. As atividades exibidas durante o jogo auxiliaram no aprimoramento da atenção concentrada, onde os exercícios são apresentados simulando situações do mundo real.

A UNICAP (Universidade Católica de Pernambuco) oferece um conteúdo relacionado a jogos digitais, utilizando técnicas e diretrizes para a construção de novas plataformas gamificadas em diversas áreas. A proposta é integrar estudantes deste curso com jovens e adultos com síndrome de down ou deficiência intelectual a fim de compreender melhor as suas necessidades e limitações. Os alunos aprendem sobre design de jogos e artes relacionadas com o tema desenvolvendo jogos digitais direcionadas a este público. Com isso, o aprendizado é proporcionado tanto aos alunos do curso de jogos digitais quanto aos jovens e adultos com deficiência intelectual (UNICAP, 2019).

O projeto APAE GAMES, desenvolvido pela UFV (Universidade Federal de Viçosa do estado de Minas Gerais) do Campus Rio Paranaíba, apresenta um jogo educacional para crianças com deficiência intelectual entre 6 e 10 anos, que visa ensinar sobre ensino básico de atividades diárias, como hábitos alimentares, higiene pessoal e memorização (FERREIRA et al., 2018). Durante os testes realizados com o público notou-se uma melhora nas habilidades motoras ao utilizar o controle remoto e na atenção concentrada porque as atividades vivenciadas durante o jogo foram exercitadas de forma recreativa e divertida.

Os ambiente virtuais de aprendizagem (AVA) podem ser considerados como ferramentas destinadas a melhorar os processos de ensino e aprendizagem do aluno por meio da inclusão de computadores e da internet (FÜLBER, 2009). Exemplos de uso de AVA para alunos com deficiência intelectual são apresentados nos estudos de Malaquias et al. (2012), Cruz (2013) e Rossi, Amorim e Santos (2020).

Malaquias et al. (2012) criou o VirtualMat, um ambiente virtual educativo para DI que permite ajudar o professor a explorar noçoes básicas de conceitos lógicomatemáticos, proporcionando organização cognitiva sobre classificação, discriminação, ordenação e sequenciamento. Cruz (2013) criou um ambiente virtual de aprendizagem para pessoas com deficiência intelectual com a finalidade de implementar atividades de letramento com o objetivo de contribuir para os estudos sobre alfabetização e letramento usando instrumentos culturais de aprendizagem cibercultura. 
Rossi, Amorim e Santos (2020) não criaram um ambiente virtual, elas utilizaram o Moodle como recurso tecnológico para o ensino de Matemática para os alunos com DI. As autoras utilizaram o moodle com o recurso de uma sala virtual com diversas atividades de matemática, onde se desenvolve os conteúdos vistos em sala de aula de uma forma diferenciada. Concluíram que o ambiente contribui para a fixação dos conteúdos estudados e permite aumentar a habilidade de abstração e raciocínio lógico dos alunos.

A aplicação de jogos sérios e ambiente virtuais para pessoas com deficiência intelectual é um tema de pesquisa que está evoluindo na área educacional. Contudo, é importante compreender o ambiente e o contexto para que os jogos e o ambiente vitual atendam adequadamente o público com deficiência intelectual.

\section{Metodologia}

Considerando a natureza desta pesquisa é aplicada, pois a partir dos conhecimentos da literatura criou-se o ambiente Ativa. Os requisitos para o desenvolvimento deste produto foram obtidos por meio de observação do comportamento dos alunos com deficiência intelectual em uma escola de educação especial da região. Esta instituição possui 106 alunos com DI (nível leve e moderado) da faixa de 16 a 80 anos de idade. Cerca de 80 alunos estão cursando a pré-escolaridade e o restante estão na escolaridade. A pré-escolaridade são alunos em fase de alfabetização enquanto os da escolaridade já sabem ler e escrever.

Os requisitos foram identificados durante o ano de 2019 (março a novembro) em que o pesquisador participou das aulas de informática dos alunos que estão na escolaridade, totalizando 25 aulas de $1 \mathrm{~h}$. Portanto, utilizou-se a pesquisa descritiva registrando e descrevendo os fatos observados sem interferir neles. O objetivo foi descrever as facilidades e dificuldades dos alunos ao acessar jogos educativos disponibilizados gratuitamente na web, em que se utilizou a coleta de dados pela observação sistemática. Observou-se a dificuldade que os alunos possuem ao acessar jogos gratuitos online por meio da digitação da $U R L$ ou mesmo digitar os dados no Google para o acessar aos jogos, por isto, a plataforma Ativa foi definida e desenvolvida.

Após a coleta de dados, iniciou-se a construção do ambiente no qual as etapas do RAD (Rapid Application Development) foram executadas conforme apresenta a Figura 1. O RAD é uma estragégia de ciclo de vida destinado a fornecer mais rápido o desenvolvimento do produto que possui algumas características que se enquadram ao Ativa como: construção baseada em módulos e equipes de desenvolvimento (MARTIN, 1992; ROSYAD et al, 2019). O Ativa foi desenvolvido como um projeto na disciplina de Padrões de Projeto de uma instituição de ensino superior da região, em que cada equipe (composta de 2 alunos), desenvolveu um módulo no ano de 2019. A responsabilidade de integração dos módulos foi atribuída para uma das equipes. $\mathrm{O}$ ambiente foi refinado na disciplina de Engenharia de Software do primeiro semestre de 2020.

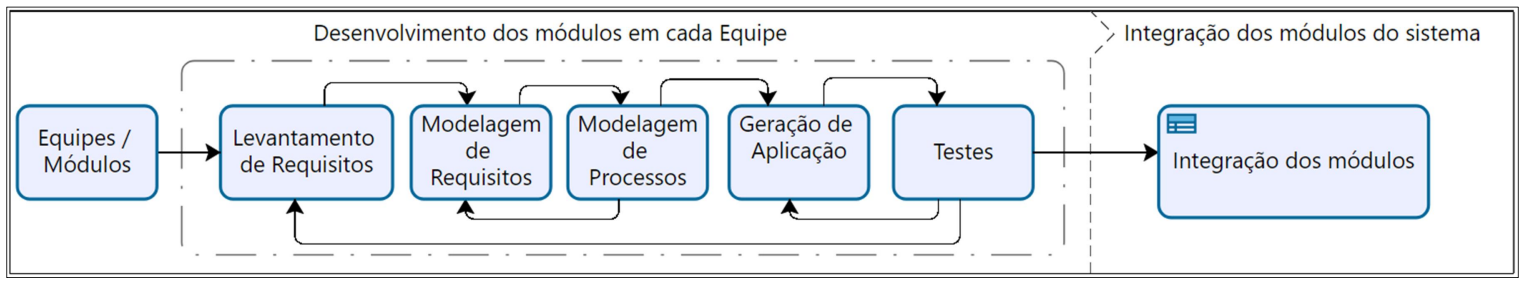

Figura 1 - Modelo de Processo para Desenvolvimento do Produto

No Levantamento de Requisitos foram realizadas as atividades de Definição dos Módulos, Prototipação da Interface Gráfica e a Definição de Requisitos. Na Definição V. $19 \mathrm{~N}^{\mathrm{o}} 1$, julho, 2021 DOI: https://doi.org/10.22456/1679-1916.118385 RENOTE 
dos módulos foram criados quatro módulos (Autenticação, Auditoria, Turma e Aula) que compõe o ambiente proposto. Na Modelagem de Requisitos foi realizada a Criação de Diagramas de Casos de Uso e a Validação por cada equipe. O processo de validação foi realizada em sala de aula com a participação do professor responsável pela disciplina e cada equipe. $O$ professor da disciplina foi responsável pela validação porque acompanhou as aulas na escola de modalidade de educação especial e conhecia o comportamento dos alunos com deficiência intelectual.

$\mathrm{Na}$ etapa de Modelagem de Processos foram criados os diagramas de classes para cada módulo para futura implementação. Na etapa de Geração da Aplicação foi realizado o desenvolvimento propriamente dito do módulo para cada equipe. A plataforma de desenvolvimento escolhida para a criação do ambiente foi a web, que tem como objetivo disponibilizar um sistema on-line para os professores e alunos. Foram utilizadas as seguintes ferramentas tecnológicas para implementação: Spring Boot (VMWARE, 2020), Thymeleaf (THYMELEAF, 2020), JPA (APACHE, 2020), Postegres (POSTGRESQL, 2020), IntelliJ IDEA Community (JETBRAINS, 2020), Bootstrap (BOOTSTRAP, 2020) e Jquery (JQUERY, 2020).

Por fim, foram realizados testes para validação do módulo, verificando se os requisitos estavam sendo atendidos ou não e ficou sob a responsabilidade de uma equipe. Outro teste realizado foi a avaliação do software por professores da educação básica na modalidade especial e para isto foi disponibilizado o software e um questionário composto de 15 perguntas.

\section{Resultados}

O Ativa é um ambiente virtual para fixação de conteúdos em que o aluno contém um conjunto de atividades de várias matérias que ele pode executar, além de permitir ao professor os gerenciamento dos assuntos e o coordenador pedagógico o gerenciamento das turmas. As atividades podem ser adicionadas na plataforma por meio de links externos de outros sites, como por exemplo, site que contemplem jogos sérios. O Ativa é composto por quatro módulos: Módulo de Autenticação, Módulo de Auditoria, Módulo de Turma, Módulo Aula que são detalhados nas próximas seções.

\subsection{Módulos do Ativa}

O módulo de Autenticação permite o acesso aos usuários ao ambiente. O ambiente pode ser acessado pelo professor, administrador ou pelo aluno. Quando acessado pelo professor, permite a ele inserir suas aulas e definir quais jogos sérios são ministrados e receber os relatórios de sua execução. $\mathrm{O}$ administrador tem a responsabilidade de gerenciar turmas, professores e alunos e ver os $\operatorname{logs}$ (eventos) do sistema. O aluno quando acessa o sistema recebe sua aula e executa o jogo estabelecido. A operação de login permite ao usuário acessar o ambiente e caso tenha esquecido sua senha ou login, o sistema permitirá a ele o reenvio da senha ou login.

O módulo de Auditoria é responsável por monitorar as atividades do sistema, assim quando uma ação é executada, por exemplo, um professor editando os dados de uma aula, ele irá adicionar na listagem da auditoria que o professor realizou tal ação. Isto é feito para todas as funcionalidades e com isso é possível ter um log do que foi realizado no ambiente. As informações de registro dos eventos realizados pelos usuários contém informações como usuário, data e hora, nome da funcionalidade, módulo, tipo de operação (inclusão, alteração e exclusão, entre outras).

O módulo de Turma é responsável pela criação das turmas, em que o administrador adiciona os alunos àquela turma referente ao ano corrente. As turmas indicam a junção de alunos que tenham as mesmas característica em termos de deficiência. Uma turma 
tem no máximo 15 alunos e pode ter aula com vários professores. Por exemplo, uma turma tem matéria de informática com um professor e de português com outro. Porém, um professor pode ministrar várias matérias. A padronização para o código da turma ficou como: as três primeiras letras do nível de escolaridade, seguido do semestre, ano e uma letra sequencial do alfabeto que representa a quantidade de turmas. Por exemplo, o código PRE0119-1 representa que a turma pertence a pré-escolaridade, do primeiro semestre de 2019 e é a primeira turma.

O módulo Aula permite o gerenciamento de matérias, assuntos e aulas. O gerenciamento de uma nova Matéria (Português, Matemática, entre outras) possui como dados necessários são: Nome da Matéria; Grau escolar (podendo ser pré-escolar, escolar ou ambos); Objetivos (breve descrição dos objetivos da disciplina) e Assuntos (temas relacionados à matéria que serão desenvolvidos). As matérias que já estiverem vinculadas com aulas não poderão ser excluídas. Exemplo de cadastro de matéria: Nome: Português; Grau escolar: Ambos; Objetivo: Desenvolver as capacidades de oralidade, leitura, escrita e produção de texto através de didáticas e abordagens diferentes; Assuntos: Alfabeto, vogais e consoantes; construção de palavras e divisão de palavras; letras maiúsculas e minúsculas; etc. Neste módulo também é controlado a execução das atividades da aula que permite o controle de aprendizagem do aluno.

Os dados necessários para o cadastro de assuntos são: Nome do Assunto e Descrição (breve descrição do assunto). Um assunto pode ser utilizado por várias matérias, por exemplo, o assunto de planetas pode ser tratado na matéria de geografia e português, do mesmo modo que o assunto de redação pode existir na matéria de português e da matemática. Isto caracteriza diferentes abordagens para um mesmo assunto.

No ambiente é possível gerar aula e cada aula é registrada por um professor e pode ser visualizada como também reutilizada por outro professor. A aula é composta por vários jogos sérios que estão relacionadas com várias matérias. Neste caso, deve-se informar a $U R L$ do jogo e o ambiente o abrirá.

\subsection{O Ambiente Proposto e Avaliação}

Conforme mencionado o ambiente proposto pode ser acessado por três tipos de usuários. Neste artigo será apresentado o ambiente do Professor e do Aluno.

A Figura 3(a) ilustra a interface do professor em que ele pode vizualizar todos os assuntos que serão trabalhados, neste caso, foi informado Estados da Água, Sistema Solar, Oralidade, entre outros. Estes assuntos foram retirados da Base Nacional Comum Curricular (BNCC) para alunos com DI da instituição de educação especial da região. No Ativa foram lançados todos os assuntos da BNCC.

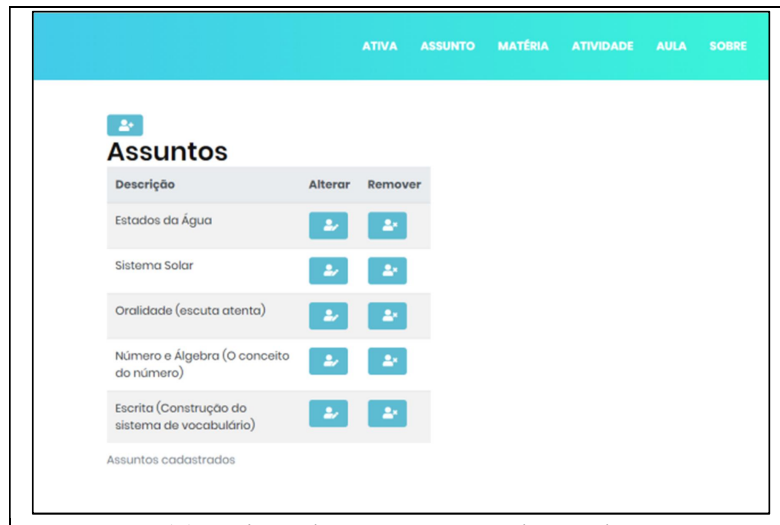

(a) Lista de Assuntos cadastrados

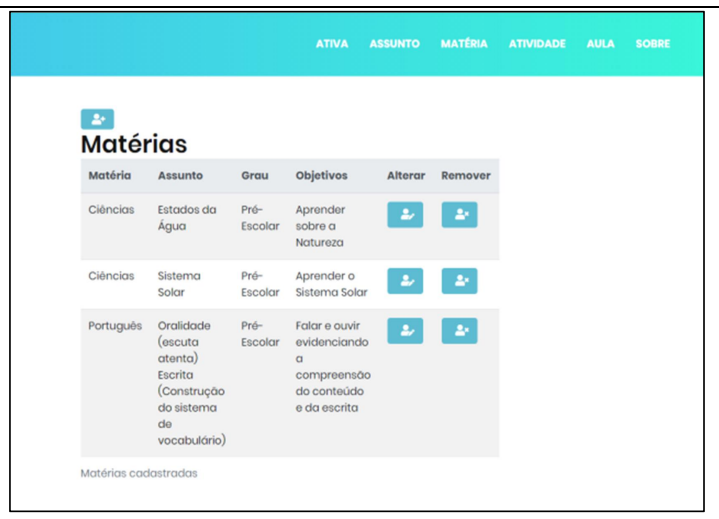

(b) Lista de Matérias cadastradas

Figura 3 - Interface para consulta de Assuntos e Matérias: Professor 
A Figura 3 (b) mostra a visualização das matérias cadastradas, sendo que as informações necessárias para seu cadastro são nome, qual o assunto, grau de escolaridade (pré-escolar, escolaridade ou ambos), objetivos e sua situação que mostra se a matéria sendo ministrada (ativa) ou não (inativa). Foi usado o tipo de grau de escolaridade "ambos", pois existem matérias que são as mesmas nos dois grau de escolaridade, o que muda é o nível de dificuldade da atividade a ser executada pelo aluno.

O lançamento da Aula é feito utilizando dados como data da aula, professor, matéria, turma e qual atividade vai realizar, confome apresenta a Figura 4. O link para o jogo já foi cadastrado quando o professor incluiu a atividade. Lembrando que uma mesma atividade pode ser utilizada por matérias diferentes. Neste também é possível controlar se o aluno executou a atividades e o tempo de execução, que proporciona o controle de aprendizagem.

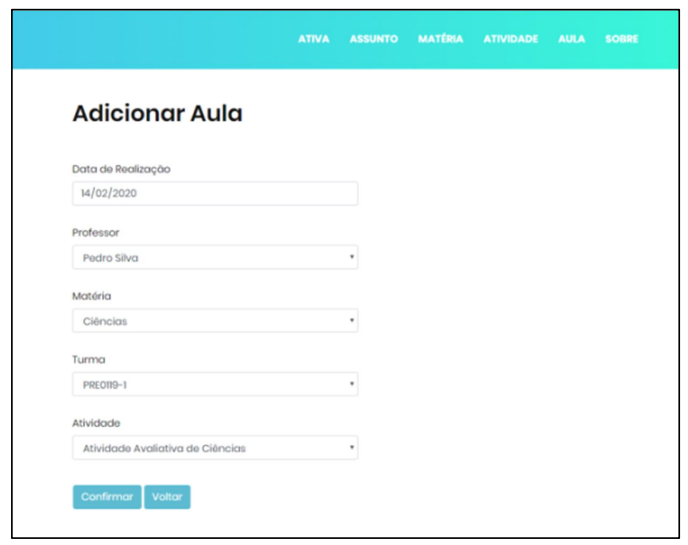

Figura 4 - Interface para consulta de matéria e lançamento da aula: Professor

A Figura 5 mostra uma das telas apresentadas ao aluno em que exibe a data e qual o jogo sério deverá ser utilizado para aquela aula. Neste exemplo, o professor realizou a configuração de duas atividades, uma de Ciências e outra de Português. O link é carregado dentro do Ativa para facilitar a visualização e interação do aluno. A atividade apresentada é referente a um jogo de ciências disponibilizado em um site educativo em que o aluno aprende os estados físicos da água e pode interagir com a atividade de forma direcionada.

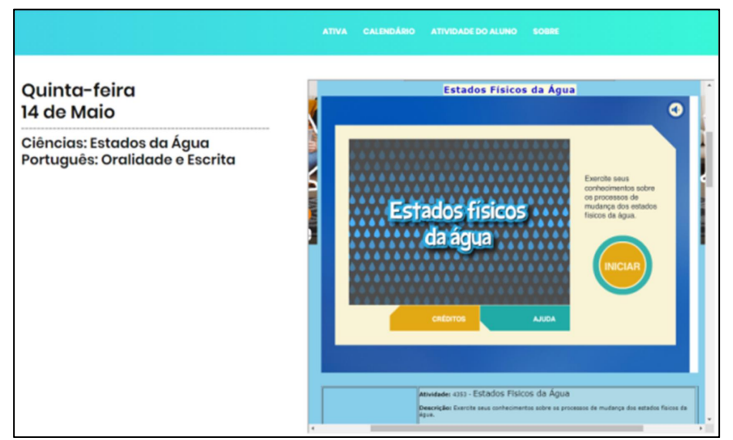

Figura 5 - Interface com a Aula: Aluno

O ambiente Ativa teve como base as características de uma pessoa com deficiência intelectual levantadas durante o acompanhamento das aulas de informática por um dos autores deste trabalho, que identificou os itens a serem aplicados no software. Dentre elas cita-se: letras em caixa alta, fonte Arial (tamanho 16), palavras significativas, simplicidade textual e de imagens e interface gráfica com poucos elementos. 
O ambiente virtual Ativa foi avaliado por 2 professores do ensino de educação especial (1 pedagoga, 1 informática), respondendo um questionário online (15 questões) conforme sua percepção sobre a relevância do software. Dentre as questões, 13 foram caracterizadas como múltipla escolha com as opções: "Sim", "Parcialmente", "Não" e "Não se aplica". E as outras 2, uma delas é subjetiva para explanar o interesse apresentado pelo software, e outra para indicar a classificação do software com as opções: "Exercício e prática", "Tutorial", "Ambiente de Aprendizagem interativo" e "Controle e conteúdo". E por último, informações adicionais para preenchimento de sugestões e comentários. A tabela 1 apresenta as perguntas do questionário aplicado.

Tabela 1 - Questionário online aplicado

\begin{tabular}{|l|l|}
\hline \multicolumn{1}{|c|}{ Perguntas do questionário } & \multicolumn{1}{|c|}{ Opção de Resposta } \\
\hline A interface gráfica do software é atraente? & Sim, Parcialmente e Não \\
\hline Existe algo interessante no software que chamou a atenção? & Subjetiva \\
\hline O software pode ser classificado como (múltipla escolha): & $\begin{array}{l}\text { Exercício e prática, Tutorial, } \\
\text { Ambiente de Aprendizagem } \\
\text { interativo e Controle e conteúdo }\end{array}$ \\
\hline $\begin{array}{l}\text { A disposição dos menus de acesso, conteúdo e funcionalidades } \\
\text { são bem distribuídas? }\end{array}$ & Sim, Parcialmente e Não \\
\hline $\begin{array}{l}\text { O funcionamento do Software está adequado para a execução e } \\
\text { controle das atividades? }\end{array}$ & Sim, Parcialmente e Não \\
\hline $\begin{array}{l}\text { O software propõe situações-problema que envolvam a } \\
\text { formulação de hipóteses, a investigação e/ou a comparação? }\end{array}$ & Sim, Parcialmente e Não \\
\hline É adequado ao público alvo? & Sim, Parcialmente e Não \\
\hline $\begin{array}{l}\text { O conteúdo do software está conectado como outros } \\
\text { conhecimentos que você já possuía? }\end{array}$ & Sim, Parcialmente e Não \\
\hline $\begin{array}{l}\text { Foi fácil entender o software e começar a utilizá-lo como } \\
\text { material de apoio? }\end{array}$ & Sim, Parcialmente e Não \\
\hline $\begin{array}{l}\text { Ao utilizar o software senti confiança de que estava aprendendo } \\
\text { utilizá-lo? }\end{array}$ & Sim, Parcialmente e Não \\
\hline $\begin{array}{l}\text { Estou satisfeito porque que terei oportunidades de utilizar o } \\
\text { software na prática em atividades que exerço? }\end{array}$ & Sim, Parcialmente e Não \\
\hline Você recomendaria o software para outras pessoas? & Sim, Parcialmente e Não \\
\hline Consegui utilizar o software por meio das minhas habilidades? & Sim, Parcialmente e Não \\
\hline Tive sentimentos positivos de eficiência ao utilizar o software? & Sim, Parcialmente e Não \\
\hline $\begin{array}{l}\text { Você acha que a experiência com o software contribuirá para seu } \\
\text { desempenho na vida profissional? }\end{array}$ & Sim, Parcialmente e Não \\
\hline Sugestões ou comentários & Subjetiva \\
\hline
\end{tabular}

Os dados coletados por meio do questionário indicaram que o software é adequado para o controle atividades educacionais ao público alvo e que agregará valores no meio profissional para auxiliar o desenvolvimento pedagógico. Contudo, algumas sugestões como a suavização da arte foram observadas para melhorar a apresentação para os alunos com deficiência intelectual. Estas questões estão sendo melhoradas para o ambiente ser usado pela escola.

\subsection{Discussões}

O aluno com deficiência intelectual pode ser estimulado a aumentar sua aprendizagem em um determinado assunto por meio de jogos sérios ou ambientes virtuais, porém estes devem estar de acordo com sua realidade e habilidades.

A criação do ambiente virtual Ativa pode apoiar os professores e alunos no processo de ensino de aprendizagem. O Ativa permite a organização dos assuntos por matérias e grau de escolaridade, armazenagem de link para os jogos sérios, o aluno tem acesso a um ambiente separado por assuntos referentes a aula que precisa fixar o conteúdo vistos em sala de aula, permite o compatilhamento de aulas entre os professores, monitoramento de execução das atividades da aula pelo aluno. Isto corrobora com a afirmação de Penterich (2005) e Fülber (2009) que dizem que um AVA

V. $19 \mathrm{~N}^{\mathrm{o}} 1$, julho, 2021

DOI: https://doi.org/10.22456/1679-1916.118385 RENOTE 
permite a gestão do ensino e aprendizagem.

$\mathrm{O}$ ambiente proposto difere dos ambientes propostos por Malaquias et al (2012) e Cruz (2013) porque sua essência está em oferecer um ambiente em que o aluno com DI possa usar jogos sérios para fixação de conteúdos, enquanto os outros ambientes proporcionam um conjunto de atividades específicas para o ensino de matemática e alfabetização, respectivamente. Porém, ambos os estudos já publicados afirmam a importância do desenvolvimento de ambientes que atendam as especificidades dos alunos com DI.

Em relação ao trabalho de Rossi, Amorim e Santos (2020) não foi criado um ambiente, os autores reutilizaram o Moodle como recurso para o ensino por meio de uma sala virtual. Diferentemente do trabalho proposto, em que se criou o Ativa que é um ambiente que atende as características dos alunos com DI, possibilita o controle da aprendizagem do aluno por meio do módulo de aula, contém uma base com os jogos educacionais gratuitos que podem são compatíveis ao público alvo e permite a reuso de aulas.

\section{Conclusão}

Este artigo apresentou um ambiente virtual de aprendizagem para alunos com deficiência intelectual, denominado de Ativa. Este ambiente foi desenvolvido usando a metodologia Rapid Application Development (RAD) e difere dos propostos por Malaquias et al (2012); Cruz (2013) e Rossi, Amorim e Santos (2020) porque permite ao professor gerenciar os assuntos de aulas por meio de jogos sérios e o aluno receber a atividade que deve ser executada no dia.

O ambiente virtual, assim como nos trabalhos de Bartolomé, Zorrilla e Zapirain (2010) e Rossi, Amorim e Santos (2020), pode ajudar a melhorar: a habilidade de atenção, fixação de conteúdos e a habilidade de coordenação motora. $\mathrm{O}$ ambiente atende as individualidades dos alunos com deficiência intelectual, permite que os professores possam reusar as aulas e controlar a aprendizagem por meio da execução das atividades. O Ativa está sendo aprimorado em relação a sua interface gráfica e será utilizado pelos alunos com defiência intelectual.

\section{Referências Bibliográficas}

ALVAREZ, J.; DJAOUTI, D.; RAMPNOUX, O. A Collaborative Classification of Serious Games. Ludoscience Studying Video Games, 2020.

Association, A. P. et al. DSM-5: Manual diagnóstico e estatístico de transtornos mentais. Porto Alegre, Brasil: Artmed Editora, 2014.

APACHE. Java Persistence API. Disponível em: $<$ http://openjpa.apache.org/> . Acesso em: 12 mar. 2020.

BARTOLOMÉ, N. A.; ZORRILLA, A. M.; ZAPIRAIN, B. G. A serious game to improve human relationships in patients with neuro-psychological disorders. In: 2nd International IEEE Consumer Electronics Society's Games Innovations Conference. [S.1.: s.n.], 2010. p. 1-5.

BIGDELI, S.; KAUFMAN, D. Digital games in medical education: key terms, concepts, and definitions. Medical Journal of the Islamic Republic of Iran (MJIRI), Iran University of Medical Sciences, v. 31, p. 1-7, sep 2017.

BOOTSTRAP. Disponível em: < https://getbootstrap.com/>. Acesso em: 12 mar. 2020.

CRUZ, M. L. R. M. da. Ambiente virtual de aprendizagem para letramento de alunos com deficiência intelectual. 2013. 242f. Tese (Doutorado em Educação) - Faculdade de Educação, Univer.do Estado do Rio de Janeiro, Rio de Janeiro, 2013. 
FARRINGTON, J. From the research: myths worth dispelling: seriously, the game is up. International Society for Performance Improvement, v. 24, p. 105-110, 2011.

FERREIRA, G. A. et al. Apae games: Um jogo digital como ferramenta de aprendizagem para crianças com deficiência intelectual. In: Proceedings - SB Games. 2018. p. 1-5. FONSECA, G. F. Planejamento e práticas curriculares nos processos de alfabetização de alunos com deficiência intelectual: experiências e trajetórias em tempos de educação inclusiva. Tese (Doutorado)- Programa de Pós-Graduação em Educação, Universidade Federal do Rio Grande do Norte, UFRN, 2016.

GUNTER, Glenda A.; KENNY, Robert F.; VICK, Erik H. Taking educational games seriously: using the retain model to design endogenous fantasy into standalone educational games. Educational Technology Research and Development, p. 511-537, 2008. HAGGLUND, P. Taking gamification to the next level: a detailed overview of the past, the present and a possible future of gamification. Tese (Doutorado) - Umea, 2012. JETBRAINS. Disp. em: $<$ https://www.jetbrains.com/pt-br/idea/ $>$. Acesso: 12 mar.20. JQUERY. Disponível em: <https://jquery.com/>. Acesso em: 12 mar. 2020.

MALAQUIAS et. al. VirtualMat: um ambiente virtual de apoio ao ensino de matemática para alunos com Deficiência Intelectual. Revista Brasileira de Informática na Educação, v. 20, n. 2, 2012.

MARTIN, J. Rapid Application Development. New Jersey: Prentice-Hall, Englewood Cliffs. Multimedia. 1992.

MELLO, G.; ZENDRON, P. Bndes setorial, n.42, set. 2015. In: [s.n.], 2015. p. 337-382. PIOVESAN, S. D. et al. Estudo exploratório: Sistema imersivo para inclusão de pessoas com deficiência no mercado de trabalho. RENOTE, 2015, v. 13, n. 1.

POSTGRESQL, Global Development Group. 2020. Disponível em: $<$ https://www.postgresql.org/>. Acesso em: 12 mar. 2020.

RICALDI, T. A. et al. EzCom: Um Recurso de Comunicação Aumentativa e Alternativa para Promover a Comunicação de Crianças com Histórico de Deficiência Intelectual.

RENOTE, 2020, v.18, n.1.

ROSSI, C. M. S.; AMORIM, D. B.; SANTOS, S. A Utilização do Moodle no Ensino Da Matemática Para Alunos Com Deficiência. REAMEC, Cuiabá (MT), v. 8, n. 2. p. 88$101,2020$.

ROSYAD, R. et al. Prayer Application for Education with Rapid Application Development Method. In: International Conference on Cyber and IT Service Management. Gabek, Indonésia. 2019.

SCHMENGLER, R. A. Contribuição do objeto de aprendizagem "Orgãos do Sentido" para alunos com deficiência intelectual. RENOTE, 2019, v.17, n.3.

THYMELEAF. Thymeleaf. The Thymeleaf Team, 2020. Disponível em: $<$ https://www.thymeleaf.org/>. Acesso em: 12 mar. 2020.

UNICAP. UNICAP. Curso Tecnológico de Jogos Digitais - UNICAP, 2019.

VENEZIANO, W. H. et al. Ferramenta educacional de tecnologia assistiva para o ensino e prática da matemática social de jovens e adultos com deficiência intelectual. In: Brazilian Symposium on Computers in Education. 2016. v. 27, n. 1, p. 886.

VINENTE, S.; GALVANI, M. D. Efeitos de um programa de reconhecimento do alfabeto emum escolar com deficiência intelectual. Pesquisa e Prática em Educação Inclusiva, v. 1, n. 2 p.268-283, 2019.

VMWARE, Inc.Spring Boot. VMware, 2020. Disponível em: $<$ https://spring.io/>. Acesso em: 12 mar. 2020. 